\title{
Downregulation of cytokeratin 18 enhances BCRP-mediated multidrug resistance through induction of epithelial-mesenchymal transition and predicts poor prognosis in breast cancer
}

\author{
RUIZAN SHI $^{1 *}$, CHANG WANG $^{1 *}$, NAIJIE FU ${ }^{1}$, LINHONG LIU $^{1}$, DIYING ZHU ${ }^{1}$, \\ ZEHUI WEI $^{2}$, HUIFENG ZHANG ${ }^{1}$, JIANFENG XING ${ }^{3}$ and YAN WANG ${ }^{1}$ \\ ${ }^{1}$ Department of Pharmacology, Shanxi Medical University, Taiyuan, Shanxi 030001; \\ ${ }^{2}$ Department of Pharmacology, Peace Hospital Affiliated to Changzhi Medical College, Changzhi, Shanxi 046000; \\ ${ }^{3}$ Medical Functional Experimental Center, Shanxi Medical University, Taiyuan, Shanxi 030001, P.R. China
}

Received September 27, 2018; Accepted March 7, 2019

DOI: $10.3892 /$ or.2019.7069

\begin{abstract}
Multiple drug resistance (MDR) and metastasis have been identified as the two major causes of the poor prognosis of patients with breast cancer. However, the relationship between MDR and metastasis has not been characterized. Epithelial-mesenchymal transition (EMT), a process known to promote metastasis in cancer, has been shown to be associated with the MDR phenotype of many tumor types. Reduced cytokeratin 18 (CK18) expression is thought to be one of the hallmarks of EMT, and the role of CK18 in MDR of metastatic breast cancer remains unknown. In the present study, we revealed that the expression of CK18 was significantly downregulated in breast cancer tissues and in an MDR cell line overexpressing breast cancer resistant protein (BCRP), and the presence of low levels of CK18 was associated with TNM stage, lymph node metastasis, and unfavorable survival in breast cancer patients. Further results demonstrated that CK18 stable knockdown using shRNA increased BCRP expression and induced the EMT process in human breast cancer MCF-7 cells. Moreover, CK18 knockdown was associated with the activation of the NF- $\mathrm{BB} /$ Snail signaling pathway, which has been revealed to regulate EMT and BCRP. Based on these findings, we concluded that CK18 knockdown enhanced BCRP-mediated MDR in MCF-7 cells through EMT induction partly via the $\mathrm{NF}-\kappa \mathrm{B} / \mathrm{Snail}$ pathway. These findings provide a valuable insight into the potential role of CK18 in MDR, migration and invasion of breast cancer cells. Reduced
\end{abstract}

Correspondence to: Dr Ruizan Shi, Department of Pharmacology, Shanxi Medical University, 56 Xinjiannan Road, Yingze, Taiyuan, Shanxi 030001, P.R. China

E-mail: shiruizan@163.com

${ }^{*}$ Contributed equally

Key words: MDR, EMT, CK18, BCRP, NF-кB/Snail signaling, breast cancer expression of CK18 may be a novel biomarker for predicting the poor prognosis of breast cancer patients.

\section{Introduction}

Breast cancer causes $\sim 500,000$ deaths worldwide each year (1). Chemotherapy plays a crucial role in treating this fatal disease (2). Although new therapeutics have been developed in the last three decades, the acquisition of multiple drug resistance (MDR) by breast cancer cells greatly impedes effective chemotherapy (3). MDR cancer cells have been revealed to exhibit greater migration/invasion abilities than their parental cells $(4,5)$. Moreover, MDR tumors are prone to relapse and metastasis $(6,7)$. MDR and metastasis are two major causes of the poor prognosis of patients with breast cancer. However, the association between MDR and metastasis and its underlying mechanism have not been characterized. Investigating the potential mechanisms underlying the aberrant metastatic capacity of MDR cells is, therefore, required for improving the efficiency of chemotherapy for advanced breast cancer.

Epithelial-mesenchymal transition (EMT) is a critical mechanism involved in the acquisition of metastatic capacity by epithelial cancer cells (8). During the EMT process, epithelial cells undergo marked morphological changes and acquire mesenchymal properties including alterations in motility, invasion, and cytoskeletal arrangements (9). The primary molecular features of EMT are the downregulation of epithelial cadherin (E-cadherin), an epithelial cell marker, and the upregulation of mesenchymal molecules, such as neural cadherin (N-cadherin) and vimentin $(10,11)$. Recent studies have revealed that EMT contributes to MDR in various tumors including breast cancer $(12,13)$. However, the mechanisms of EMT-promoted MDR in breast cancer remain poorly understood.

Cytokeratin 18 (CK18), which is known to maintain cellular structural integrity and resist external stresses applied to cells, has been recognized as an epithelial-specific marker of the EMT process $(14,15)$. CK18 also affects various cellular processes such as cell cycle progression, apoptosis, mitosis, and cell signaling (16). Downregulation of CK18 has been revealed to induce EMT and promote cancer cell migration $(17,18)$. 
Reduced expression of CK18 was revealed to promote the progression of breast tumors (19), while its increased expression, accordingly, predicted a favorable prognosis in patients with breast cancer (20). Additionally, aberrant CK18 expression has been linked to apoptosis resistance $(21,22)$. However, whether CK18 regulates ATP-binding cassette (ABC) transporter-mediated MDR has not been experimentally confirmed.

We hypothesized that CK18 downregulation induces the EMT process, enhances MDR, and is associated with poor therapeutic outcomes in breast cancer. In the present study, we assessed CK18 expression in breast cancer tissues and determined the association between CK18 and human breast cancer prognosis. Moreover, the functional involvement of CK18 was examined in a mitoxantrone (MX)-selected MCF-7/MX cell line that overexpressed breast cancer resistant protein (BCRP) as well as in its parental human breast cancer MCF-7 cells. Investigating and confirming the importance of CK18 in MDR and EMT may provide a potential predictor and treatment strategy for patients with breast cancer.

\section{Materials and methods}

Tissue samples and clinical data collection. Sixty samples from breast cancer tissues and 15 samples from matched adjacent non-tumor tissues (ANTTs) were collected at the Shanxi Cancer Hospital (Taiyuan, China) from August 2012 to March 2013. The diagnosis was confirmed by two pathologists at Shanxi Cancer Hospital. The age of the patients ranged from 31 to 76 years (median age, 54 years). Before biopsy sampling, none of the patients were subjected to chemotherapy or radiotherapy. ANTT was obtained $>3 \mathrm{~cm}$ away from the tumor tissues. Clinicopathological characteristics including age, family history, tumor size, lymph node metastasis, tumor-node-metastasis (TNM) stage, histological grade, and expression of estrogen receptor (ER), progesterone receptor (PR), HER-2, Ki-67 and E-cadherin were obtained from hospital records. Other relevant clinical information was also collected, including disease-free survival (DFS), as the interval between date of diagnosis and date of recurrence; overall survival (OS), as the interval from date of surgery to death, and current patient status.

Ethics statement. Use of the specimens was approved by the Ethics Committee of Shanxi Cancer Hospital. All experimental protocols were approved by the Ethics Committee of Shanxi Medical University (Taiyuan, China). All patients provided written informed consent before participation in this study.

Immunohistochemical (IHC) staining and evaluation. IHC staining was performed using a streptavidin-peroxidase procedure as previously described (23). Briefly, tissue sections of tumor samples (3- $\mu \mathrm{m}$ thickness) were dewaxed, rehydrated, and treated with $3 \%$ hydrogen peroxide for $10 \mathrm{~min}$ to inhibit the activity of endogenous peroxidase. Non-specific binding sites were blocked with $10 \%$ normal goat serum. The tumor sections were incubated overnight at $4^{\circ} \mathrm{C}$ with the anti-CK18 antibody (dilution 1:600; cat. no. 10830-1-AP; ProteinTech Group Inc.; Wuhan Sanying Biotechnology, Wuhan, China), followed by a 30-min incubation with a biotinylated secondary antibody (cat. no. PV-6000; Beijing Zhongshan Golden Bridge Biotechnology Co., Ltd., Beijing, China) at $37^{\circ} \mathrm{C}$.

IHC results were analyzed by a semi-quantitative method according to staining intensity and positive cell percentage. Staining intensity was scored as: 0 (negative), 1 (weakly positive), 2 (moderately positive) and 3 (strongly positive). The percentage of stained cells was scored as: $0(<5 \%), 1(5-25 \%$ positive), 2 (26-50\% positive), 3 (51-75\% positive), 4 (>76\% positive). The final IHC score was determined by multiplying the intensity and percentage score (range $0-12$ ). A score $\geq 7$ was defined as CK18 high expression, and scores $<7$ were defined as CK18 low expression.

Cell culture. Human breast cancer MCF-7 and MCF-7/MX cells were kindly provided by Dr E. Schneider (Wadsworth Center, New York, NY, USA). Cells were grown in RPMI-1640 culture medium containing $10 \%$ fetal bovine serum (FBS) (both from Gibco; Thermo Fisher Scientific, Inc., Waltham, MA, USA) in an incubator humidified at $37^{\circ} \mathrm{C}$ with $5 \% \mathrm{CO}_{2}$. MCF-7/MX cells were cultured in RPMI-1640 medium containing $400 \mathrm{ng} / \mathrm{ml} \mathrm{MX}$ (Sigma-Aldrich; Merck KGaA, Darmstadt, Germany) to maintain their MDR phenotype and transferred to drug-free medium for at least two weeks before experimentation.

Morphological analysis. Cells were seeded into 6-well plates at $5 \times 10^{5}$ cells/well in $2 \mathrm{ml}$ of medium. The cell morphology was observed and photographed under an inverted microscope (Leica Microsystems GmbH, Wetzlar, Germany) at a magnification of $\mathrm{x} 200$.

Cytotoxicity assay. Cell cytotoxicity was analyzed using the Cell Counting Kit-8 (CCK-8) (Wuhan Boster Biological Technology,Ltd., Wuhan,China). Cells were cultured in 96-well plates at a density of $1.8 \times 10^{3}$ cells/well. After incubation for $24 \mathrm{~h}$, the cells were treated with various concentrations of MX, fluorouracil (5-FU), doxorubicin (Dox), cytarabine (Ara-C), or cisplatin (DDP) (all from Sigma-Aldrich; Merck KGaA) for another $70 \mathrm{~h}$, and then incubated with $10 \%$ CCK-8 reagent for an additional $2 \mathrm{~h}$. Cell viability was evaluated at $450 \mathrm{~nm}$ on an automated microplate reader (BioTek Instruments, Inc., Winooski, VT, USA). Cells treated without chemotherapeutic agents were used as controls. All CCK- 8 tests were performed in triplicate and repeated three times. The $\mathrm{IC}_{50}$ values were calculated using SPSS software (version 23.0; IBM Corp., Armonk, NY, USA). The cell survival rate was quantified as the number of live cells divided by the total number of cells and calculated as follows: Cell survival rate $(\%)=$ optical density (OD) value of experimental well/OD value of control well $x 100 \%$. The resistance fold (RF) was defined as the $\mathrm{IC}_{50}$ (MCF-7/MX or MCF-7/siCK18)/IC 50 (MCF-7).

Cell proliferation assay. Cells were seeded in 96-well plates at a density of $1 \times 10^{3}$ cells/well and cultured for up to three days. Cell proliferation capacity was then assessed every $24 \mathrm{~h}$ by CCK- 8 assay as aforementioned. Ten duplicate wells were prepared for each sample.

Migration and invasion assays. Cell migration and invasion potentials were assessed using 24-well Transwell chambers 
(Corning Incorporated, Corning, NY, USA) coated with or without Matrigel Matrix (Sigma-Aldrich; Merck KGaA). Briefly, $\sim 1 \times 10^{5}$ (migration) or $2 \times 10^{4}$ (invasion) cells were suspended in the upper well of the chamber in RPMI-1640 medium without FBS. Medium containing serum was placed in the lower well and served as a chemoattractant. After $48 \mathrm{~h}$, the upper chamber of the filter was scraped gently to remove the nonmigratory cells. Migrated and invaded cells were fixed, stained with $0.3 \%$ crystal violet, photographed, and counted under an inverted microscope (Leica Microsystems $\mathrm{GmbH}$ ). Each assay was performed on triplicate filters.

Plasmids and stable transfection. MCF-7 cells were plated in 6-well plates and incubated for $24 \mathrm{~h}$; transfection was then performed with CK18-specific (pSilencer 3.1/CK18) or non-silencing negative control (pSilencer 3.1/NC) expression vector constructs using Lipofectamine 2000 (Beijing SBS Genetech Co., Ltd., Beijing, China). Stable clone cells were selected with $500 \mu \mathrm{g} / \mathrm{ml} \mathrm{G}$-418 sulfate (G418) (Beijing Solarbio Science \& Technology Co., Ltd., Beijing, China). Downregulated expression of the CK18 gene and protein was determined by quantitative real-time polymerase chain reaction (PCR) and western blotting, respectively.

The siRNA oligonucleotide sequences used for CK18 and NC were: 5'-gatccgAGAGGAGCTAGACAAGTACttcaagagaGTA CTTGTCTAGCTCCTCTCtttttt-3' and 5'-atccgCTTACAATCA GACTGGCGAttcaagagaTCGCCAGTCTGATTGTAAGtttttt-3', respectively. The validity of the inserts was verified by sequence analysis (Invitrogen; Thermo Fisher Scientific, Inc., Waltham, MA, USA).

Reverse transcriptase andquantitative real-time PCR. Total RNA was isolated from cells by TRIzol reagent (Invitrogen; Thermo Fisher Scientific, Inc.), and cDNA was synthesized from $1 \mu \mathrm{g}$ of total RNA using Transcript First-Strand cDNA Synthesis SuperMix (Beijing Transgen Biotech Co., Ltd., Beijing, China). The mRNA levels of Snail, N-cadherin, E-cadherin, NF- $\kappa \mathrm{B}$ (p65), vimentin, BCRP, and internal control $\beta$-actin were detected. PCR products were separated by electrophoresis on $1-2 \%$ agarose gels, imaged on a GelDoc ${ }^{\mathrm{TM}} \mathrm{XR}$ (Bio-Rad Laboratories, Inc., Hercules, CA, USA), and quantified by densitometry using Image Lab software (version 5.2.1; Bio-Rad Laboratories, Inc.). Real-time PCR was performed with Power SYBR-Green PCR SuperMix (Mei5 Biotechnology, Co., Ltd., Beijing, China), using a CFX96 Touch Detection System (cat. no. 1855195; Bio-Rad Laboratories, Inc.). The fold-change value of CK18 mRNA was normalized to $\beta$-actin using the $\Delta \Delta \mathrm{Cq}$-method (24). The gene-specific primer pairs were as follows ( $\left.5^{\prime}-3^{\prime}\right)$ : Snail forward, GCCTTCAACTGCAAA TACTGC and reverse, CTTCTTGACATCTGAGTGGGTC; $\mathrm{N}$-cadherin forward, GATGTTGAGGTACAGAATCGT and reverse, GGTCGGTATGGATGGCGA; E-cadherin forward, ATTCTGATTCTGCTGCTCTTG and reverse, AGTAGTCA TAGTCCTGGTCTT; NF-кB (p65) forward, AGGCTCTGTG CGTGTCTCC and reverse, GGGTGGGCTTGGGGGCAGGT; vimentin forward, TCGCCAACTACATCGACAAG and reverse, AAGATTGCAGGGTGTTTTCG; BCRP forward, TGTTTGGAAGGTCCGGGTGA and reverse, CATGATCCC ATTGTAATTCG; $\beta$-actin forward, CTGGGACGACATGG AGAAAA and reverse, AAGGAAGGATGGAAGAGTGC.
PCR amplification was performed with denaturation at $94^{\circ} \mathrm{C}$ for $30 \mathrm{sec}$, annealing at $55^{\circ} \mathrm{C}$ for $40 \mathrm{sec}$, and extension at $72^{\circ} \mathrm{C}$ for $1 \mathrm{~min}$ in 35 cycles.

Western blot analysis. A western blot assay was carried out as previously described (25). Cell lysates containing $50 \mu \mathrm{g}$ of total protein were resolved by sodium dodecyl sulfate-polyacrylamide gel electrophoresis (SDS-PAGE) and transferred onto nitrocellulose membranes. The membranes were incubated with specific primary antibodies against BCRP (dilution 1:1,000; cat. no. D160018), lung resistance protein (LRP) (dilution 1:1,000; cat. no. D220930) (both from Shanghai Sangong Pharmaceutical Co., Ltd., Shanghai, China), multidrug resistance protein (MRP) (dilution 1:1,500; cat. no. D260613; Shanghai Sangong Pharmaceutical Co., Ltd.), P-glycoprotein (P-gp) (dilution 1:500; cat. no. PB0162; Wuhan Boster Biological Technology, Ltd.), CK18 (dilution 1:2,000; cat. no. 10830-1-AP; ProteinTech; Wuhan Sanying Biotechnology, Wuhan, China), E-cadherin (dilution 1:1,000; cat. no. 14472), Snail (dilution 1:1,000; cat. no. 3879), N-cadherin (dilution 1:500; cat. no. 14215) (all from Cell Signaling Technology, Inc., Danvers, MA, USA), NF-кB p65 (dilution 1:1,000; cat. no. D120135; Shanghai Sangong Pharmaceutical Co.), vimentin (dilution 1:700; cat. no. ab92547; Abcam, Cambridge, UK), and $\beta$-actin (dilution 1:5,000; cat. no. BM0627; Wuhan Boster Biological Technology, Ltd.) overnight at $4^{\circ} \mathrm{C}$. After incubation for $1 \mathrm{~h}$ with corresponding horseradish peroxidase (HRP)-linked secondary antibody (dilution 1:5,000; cat. no. ZB-2301/2305), the blots were detected using the electrochemiluminescence (ECL) system (Bio-Rad Laboratories, Inc., Hercules, CA, USA). The band density was quantified by densitometry using Image Lab software (version 5.2.1; Bio-Rad Laboratories, Inc.).

Statistical analysis. All quantitative data are presented as the means \pm standard deviations (SDs) from at least three independent experiments. Fisher' s exact test was used to evaluate associations between CK18 expression and the clinicopathological characteristics of breast cancer. Survival curves were estimated using the Kaplan-Meier method and compared by a log-rank test. Differences between two samples were analyzed by Student's t-test, and multiple comparisons were performed by one-way analysis of variance (ANOVA) and the Student-Newman-Keuls (SNK) test using SPSS software (version 23.0; SPSS, Inc., Chicago, IL, USA). P<0.05 (two-tailed) was considered to indicate a statistically significant difference.

\section{Results}

CK18 is downregulated in tumor tissues and correlated with lymph node metastasis of breast cancer. We determined the expression levels of CK18 in human breast cancer specimens and ANTT using IHC staining. Representative images are presented in Fig. 1A. CK18 was mainly localized at the cell membrane and the cytoplasm. CK18 immunoreactivity was consistently weaker in primary breast cancer tissue $(\mathrm{P}<0.01)$ and even less in metastatic lesions $(\mathrm{P}<0.001)$ than in normal breast tissues (Fig. 1B). We classified the patients into a CK18 low- and a high-expression group according to its IHC 
Table I. Associations between the expression level of CK18 and the clinicopathological characteristics of patients with breast cancer.

\begin{tabular}{|c|c|c|c|c|}
\hline \multirow[b]{2}{*}{ Variables } & \multirow[b]{2}{*}{$\begin{array}{l}\text { Cases } \\
(n=60)\end{array}$} & \multicolumn{2}{|c|}{ CK18 expression } & \multirow[b]{2}{*}{ P-value } \\
\hline & & $\begin{array}{c}\text { Low } \\
(n=37)\end{array}$ & $\begin{array}{l}\text { High } \\
(n=23)\end{array}$ & \\
\hline Age (years) & & & & 0.4313 \\
\hline$\leq 50$ & 33 & 22 & 11 & \\
\hline$>50$ & 27 & 15 & 12 & \\
\hline Family history & & & & 0.9999 \\
\hline Yes & 7 & 4 & 3 & \\
\hline No & 53 & 33 & 20 & \\
\hline Tumor size (cm) & & & & 0.0518 \\
\hline$<5$ & 57 & 37 & 20 & \\
\hline$\geq 5$ & 3 & 0 & 3 & \\
\hline Lymph node metastasis & & & & $0.0088^{b}$ \\
\hline Yes & 34 & 26 & 8 & \\
\hline No & 26 & 11 & 15 & \\
\hline AJCC TNM stage & & & & $0.0205^{\mathrm{a}}$ \\
\hline $\mathrm{I}+\mathrm{II}$ & 48 & 26 & 22 & \\
\hline III & 12 & 11 & 1 & \\
\hline Histological grade & & & & 0.9999 \\
\hline $\mathrm{I}+\mathrm{II}$ & 47 & 29 & 18 & \\
\hline III & 13 & 8 & 5 & \\
\hline ER & & & & 0.9999 \\
\hline+ & 45 & 28 & 17 & \\
\hline- & 15 & 9 & 6 & \\
\hline PR & & & & 0.4041 \\
\hline+ & 39 & 26 & 13 & \\
\hline- & 21 & 11 & 10 & \\
\hline HER-2 & & & & 0.7215 \\
\hline+ & 9 & 5 & 4 & \\
\hline- & 51 & 32 & 19 & \\
\hline Ki-67 (\%) & & & & 0.7650 \\
\hline$\leq 14$ & 16 & 9 & 7 & \\
\hline$>14$ & 44 & 28 & 16 & \\
\hline E-cadherin & & & & $0.0014^{\mathrm{b}}$ \\
\hline++ & 29 & 25 & 4 & \\
\hline+ & 31 & 12 & 19 & \\
\hline
\end{tabular}

${ }^{\mathrm{a}} \mathrm{P}<0.05,{ }^{\mathrm{b}} \mathrm{P}<0.01$, Fisher's exact test; AJCC, American Joint Committee on Cancer; TNM, tumor-node-metastasis; ER, estrogen receptor; $\mathrm{PR}$, progesterone receptor.

staining results, and the associations between CK18 level and clinicopathological characteristics of patients with breast cancer were analyzed. Low expression of CK18 was associated with TNM stage, lymph node metastasis, and E-cadherin expression (Table I). Follow-up analysis was performed to analyze the association of CK18 expression and breast cancer prognosis. A significant tendency of CK18 downregulation
Table II. The resistance of MCF-7 and MCF-7/MX cells to different chemotherapeutic agents.

\begin{tabular}{lccc}
\hline & \multicolumn{2}{c}{$\mathrm{IC}_{50}(\mathrm{nmol} / \mathrm{l}) \pm \mathrm{SD}^{\mathrm{a}}$} & \\
\cline { 2 - 3 } Drugs & $\mathrm{MCF}-7$ & $\mathrm{MCF}-7 / \mathrm{MX}$ & Resistance fold \\
\hline MX & $35.6 \pm 0.9$ & $1484.2 \pm 43.2^{\mathrm{a}}$ & 41.7 \\
Ara-C & $6.5 \pm 0.8$ & $676.1 \pm 91.5^{\mathrm{a}}$ & 104.0 \\
Dox & $475.7 \pm 1.3$ & $18577.0 \pm 1372.4^{\mathrm{a}}$ & 39.1 \\
DDP & $464.2 \pm 16.6$ & $4544.3 \pm 220.6^{\mathrm{a}}$ & 9.8 \\
5-FU & $271.5 \pm 6.1$ & $5507.7 \pm 153.9^{\mathrm{a}}$ & 20.3
\end{tabular}

${ }^{\mathrm{a}} \mathrm{IC}_{50}$ values were calculated from three independent experiments performed in triplicates; ${ }^{\mathrm{a}} \mathrm{P}<0.001$ compared to MCF-7 cells. SD, standard deviation; MX, mitoxantrone; Ara-C, cytarabine; Dox, doxorubicin; DDP, cisplatin; 5-FU, fluorouracil.

towards unfavorable prognosis was displayed in analysis of DFS (Fig. 1C). A similar trend was observed in OS analysis, and patients with low-level CK18 expression had shorter OS durations than those with high-level CK18 expression, although the trend was not statistically significant (log-rank $\mathrm{P}=0.3844$ ) (Fig. 1D).

Cell migration is enhanced in MCF-7/MX cells that overexpress BCRP. MCF-7/MX cells were $\sim 42$ times more resistant to $\mathrm{MX}$ than parental cells (Fig. 2A and Table II). MCF-7/MX was also cross-resistant to Ara-C, Dox, DDP and 5-FU, and the $\mathrm{IC}_{50}$ values of these drugs for $\mathrm{MCF}-7 / \mathrm{MX}$ cells were significantly increased $(\mathrm{P}<0.001$ in all 4 cases; Table II). The expression of four MDR proteins (BCRP, P-gp, MRP and LRP) was investigated in these two cell lines. BCRP levels in MCF-7/MX cells were markedly upregulated and $\sim$-fold higher than those in the parental cells $(\mathrm{P}<0.001)$; MRP and LRP were only slightly more upregulated in MCF-7/MX cells than in MCF-7 cells $(\mathrm{P}>0.05)$; and $\mathrm{P}-\mathrm{gp}$ expression was not detected in either cell line (Fig. 2B and C). These results confirmed that BCRP overexpression was the primary contributor to MDR in MCF-7/MX cells.

Whereas parental MCF-7 cells exhibited an epithelial cobblestone phenotype, MCF-7/MX cells exhibited spindle-shaped, fibroblastoid-like morphology (Fig. 2D), increased cell migration and invasion (Fig. 2E and F), downregulated E-cadherin, and upregulated N-cadherin and vimentin (Fig. 2G), suggesting that MDR MCF-7/MX cells underwent EMT and acquired a more powerful motile capacity. Additionally, lower levels of CK18 mRNA and protein were detected in MCF-7/MX than in MCF-7 cells (Fig. 2H and I). These results indicated that CK18 may participate in BCRP-mediated MDR in breast cancer cells.

Downregulation of CK18 enhances the chemoresistance of $\mathrm{MCF}-7$ cells. After selection, two stable clones, MCF-7/siCK18-7D and MCF-7/siCK18-3C, were obtained. CK18 mRNA expression was 56.3\% $(\mathrm{P}<0.001)$ and $81.8 \%$ $(\mathrm{P}<0.001)$ lower in MCF-7/siCK18-7D and -3C cells, respectively, than in MCF-7 cells (Fig. 3A). Representative western 
A

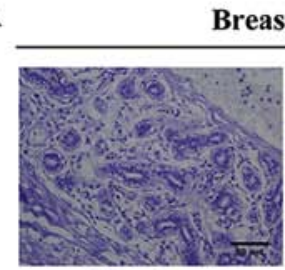

Negative

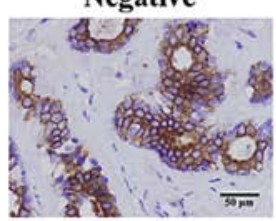

Medium

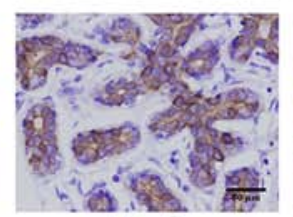

Weak

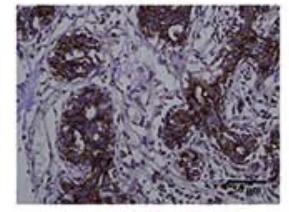

Positive
ANTT

B

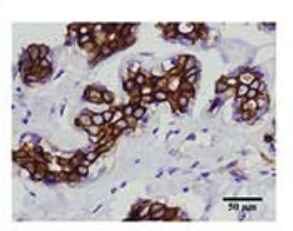

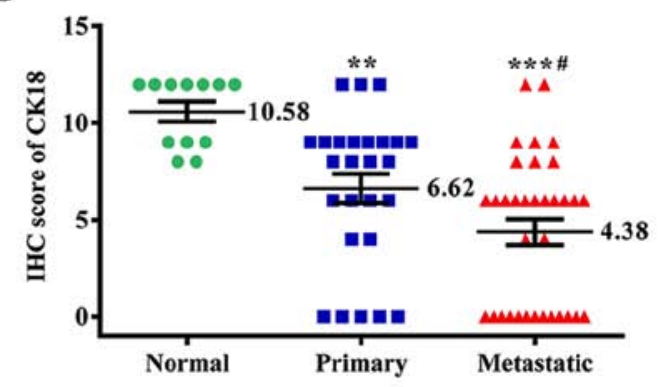

D

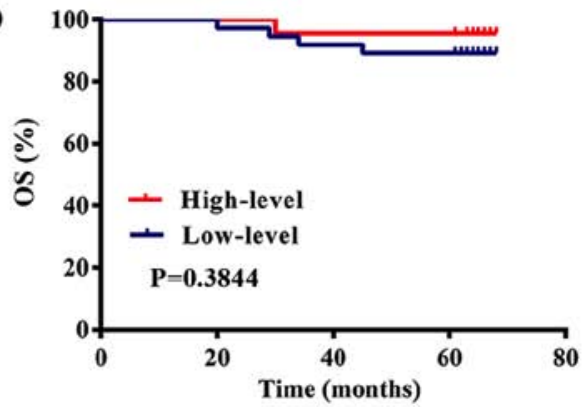

Figure 1. Low expression of CK18 predicts poor prognosis in breast cancer. (A) Representative immunohistochemical staining of CK18 protein in breast cancer tissues and ANTT (original magnification, $\mathrm{x} 400$ ). (B) Distribution of CK18 IHC scores in ANTT, primary, and metastatic breast cancer. ${ }^{* *} \mathrm{P}<0.01$, ${ }^{* * * * *} \mathrm{P}<0.001$ vs. normal, ${ }^{\text {}} \mathrm{P}<0.05$ vs. primary. Breast cancer patients with lower CK18 expression had poorer (C) DFS and (D) OS than those with higher CK18 expression. ANTT, adjacent non-tumor tissue; IHC, immunohistochemistry; DFS, disease-free survival; OS, overall survival.
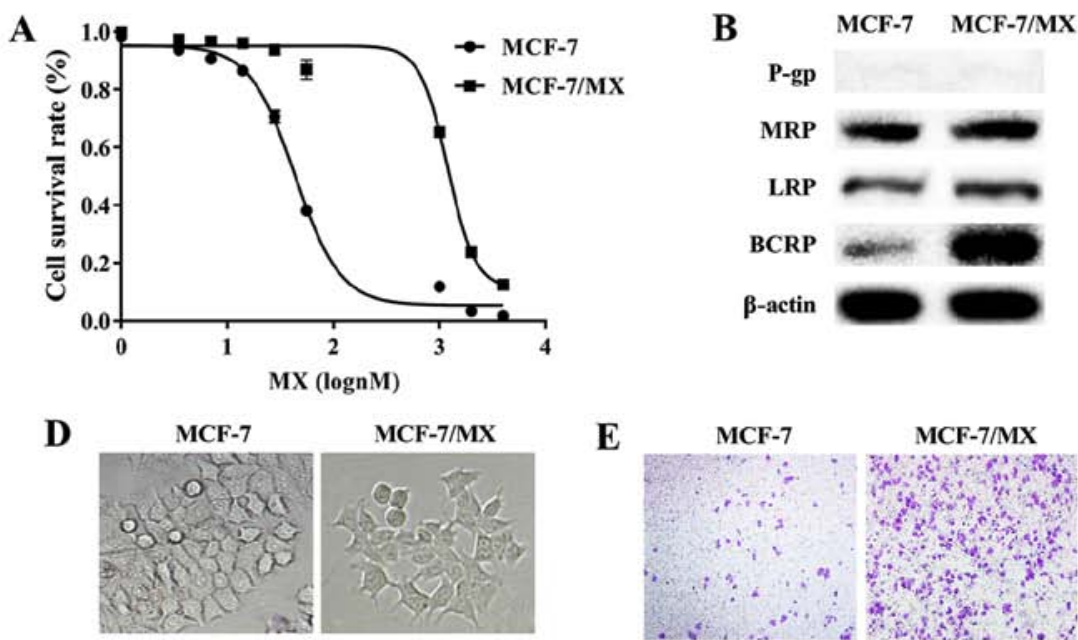

G

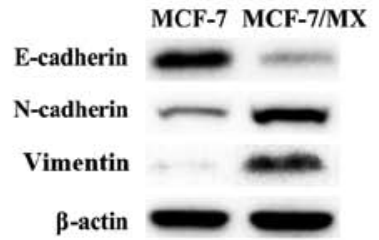

$\mathbf{E}$

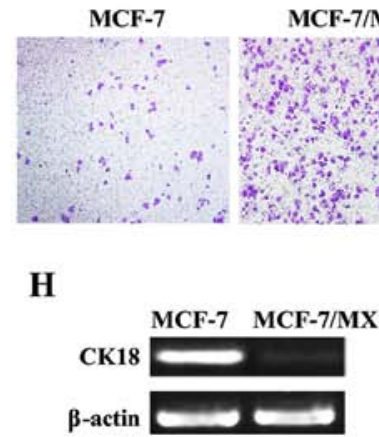

C

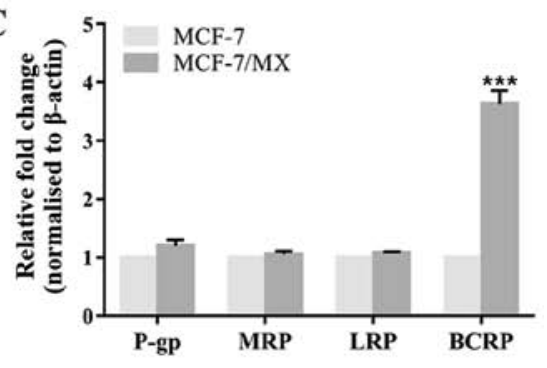

F

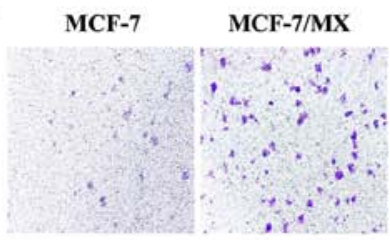

I

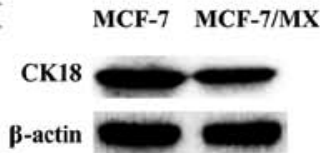

Figure 2. CK18 expression is decreased in MDR MCF-7/MX cells with mesenchymal properties. (A) The cell survival rate was analyzed in resistant MCF-7/MX and parental MCF-7 cells $72 \mathrm{~h}$ after treatment with different concentrations of MX. (B) The expression of P-gp, MRP, LRP and BCRP proteins was determined by western blot analyses in MCF-7 and MCF-7/MX cells. (C) P-gp, MRP, LRP and BCRP protein expression was normalized to the $\beta$-actin levels. ${ }^{* * *} \mathrm{P}<0.001$ vs. MCF-7 cells. (D) Morphology of MCF-7/MX and MCF-7 cells. The images were captured at a magnification of x200. (E) The migration and (F) invasion abilities of MCF-7/MX and MCF-7 cells were evaluated using Transwell chambers covered with or without Matrigel. Cells were stained with crystal violet; the images were captured at a magnification of x100. (G) Representative western blot images of epithelial markers E-cadherin and mesenchymal markers N-cadherin and vimentin in MCF-7/MX and MCF-7 cells. (H) The mRNA and (I) protein expression levels of CK18 in MCF-7 and MCF-7/MX cells were determined by RT-PCR and western blot analyses. In all cases, images are representative of three to four independent experiments. MX, mitoxantrone; MRP, multidrug resistance protein; LRP, lung resistance protein; BCRP, breast cancer resistant protein. 
Table III. Effects of CK18 downregulation on chemosensitivity of MCF-7/MX cells to chemotherapeutic agents.

\begin{tabular}{|c|c|c|c|}
\hline \multirow[b]{2}{*}{ Cells } & \multicolumn{3}{|c|}{$\mathrm{IC}_{50}(\mathrm{nmol} / \mathrm{l}) \pm \mathrm{SD}^{\mathrm{a}}(\mathrm{RR})^{\mathrm{b}}$} \\
\hline & MX & Ara-C & Dox \\
\hline MCF-7 & $35.6 \pm 0.9(1)$ & $6.5 \pm 0.8(1)$ & $475.7 \pm 1.3(1)$ \\
\hline MCF-7/siNC & $42.3 \pm 2.7(1.2)$ & $7.3 \pm 1.4(1.1)$ & $410.2 \pm 72.5(0.9)$ \\
\hline MCF-7/siCK18-7D & $174.7 \pm 24.7\left(4.9^{\mathrm{c}}\right.$ & $38.8 \pm 2.2(6.0)$ & $713.3 \pm 121.4(1.5)^{\mathrm{c}}$ \\
\hline MCF-7/siCK18-3C & $672.0 \pm 55.0(18.9)^{\mathrm{c}, \mathrm{d}}$ & $165.5 \pm 54.7(25.5)^{\mathrm{c}, \mathrm{d}}$ & $2268.4 \pm 158.2(4.8)^{\mathrm{c}, \mathrm{c}}$ \\
\hline
\end{tabular}

A

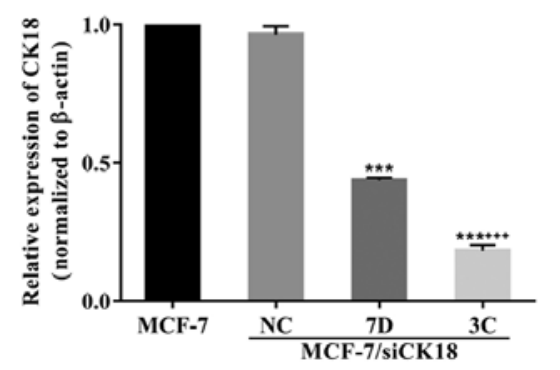

C

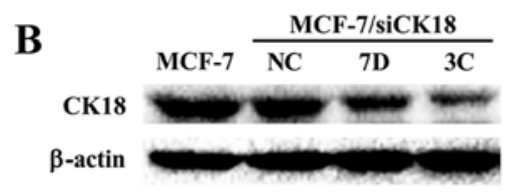

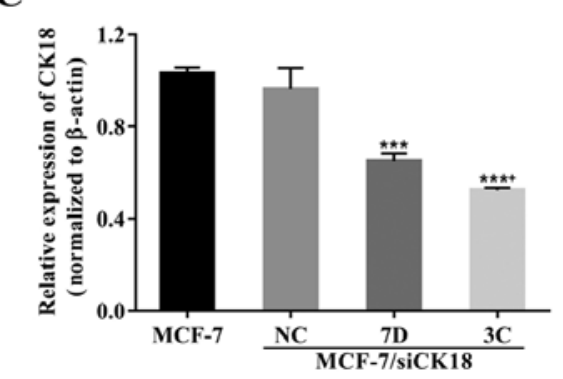

Figure 3. Transfection and interference of CK18 in parental MCF-7 cells. (A) The relative expression of the CK18 gene in cells was examined by quantitative real-time PCR. The CK18 mRNA levels in MCF-7 cells were set at 100\%. (B) Representative western blot images of CK18 in MCF-7, MCF-7/siNC, and MCF-7/siCK18 cells. (C) CK18 protein expression was normalized to the $\beta$-actin levels. Bar graphs represent the mean \pm standard deviation (SD) of three independent experiments. ${ }^{* * *} \mathrm{P}<0.001$ vs. MCF-7 cells; ${ }^{+} \mathrm{P}<0.05$ and ${ }^{+++} \mathrm{P}<0.001$ vs. MCF-7/siCK18-7D cells.

blotting revealed a significant downregulation of CK18 expression in MCF-7/siCK18 cells, while approximately equal amounts of CK18 protein were observed in MCF-7/siNC and MCF-7 cells (Fig. 3B). CK18 protein levels were 37.0\% $(\mathrm{P}<0.001)$ and $49.2 \%(\mathrm{P}<0.001)$ lower in MCF-7/siCK18-7D and $-3 \mathrm{C}$ cells, respectively, than in MCF-7 cells (Fig. 3C).

Downregulation of CK18 in MCF-7 cells significantly enhanced resistance to several chemotherapeutic agents (Table III).Compared to MCF-7 cells, the resistance of MCF-7/siCK18-7D cells to MX, Ara-C and Dox was increased to 4.9- $(\mathrm{P}<0.001), 6.0$ - and 1.5 -fold $(\mathrm{P}<0.001)$, respectively, while that of MCF-7/siCK18-3C cells was increased to 18.9-, 25.5- and 4.8-fold $(\mathrm{P}<0.001$ in all three cases), respectively. The $\mathrm{IC}_{50}$ values of these chemotherapeutic agents in MCF-7/siNC were close to those in MCF-7 cells ( $\mathrm{P}>0.05)$.

Downregulation of CK18 in MCF-7 cells promotes BCRP expression. The BCRP gene was markedly upregulated in MCF-7/siCK18 cells compared with that in MCF-7 cells (Fig. 4A). Quantification results revealed that BCRP mRNA levels were $277.8 \%(\mathrm{P}<0.001)$ and $365.6 \%(\mathrm{P}<0.001)$ greater in MCF-7/siCK18-7D and -3C cells, respectively, than in MCF-7 cells (Fig. 4B). CK18 downregulation also induced an increase in BCRP protein levels, as determined by western blot analysis (Fig. 4C). The expression of BCRP protein was $37.8 \%(\mathrm{P}<0.01)$ and $72.3 \%(\mathrm{P}<0.001)$ greater in MCF-7/siCK18-7D and -3C cells, respectively, than in MCF-7 cells, while no significant increase in BCRP levels was observed in MCF-7/siNC cells ( $\mathrm{P}>0.05$ ) (Fig. 4D).

CK18 downregulation increases cell motility and invasion capacity. In contrast to the epithelial cobblestone phenotype of MCF-7 and MCF-7/siNC cells, MCF-7/siCK18 cells exhibited elongated, fibroblastic morphology which was similar to that of MCF-7/MX cells (Fig. 5A). As revealed in Fig. 5B-E, the number of MCF-7/siNC cells that migrated through the permeable membrane or invaded through the Matrigel-coated membrane was approximately equal to that of MCF-7 cells ( $\mathrm{P}>0.05)$, while MCF-7/siCK18-7D and -3C cells demonstrated greater migration $(\mathrm{P}<0.001)$ and invasion abilities $(\mathrm{P}<0.01$ and $\mathrm{P}<0.001$, respectively), than MCF-7 cells. There were no significant differences in cell proliferation ability between the four cell lines ( $\mathrm{P}>0.05$; Fig. 5F), suggesting that the increase in cell migration and invasion was not due to enhanced proliferation.

CK18 downregulation modulates the expression of EMT markers. To further determine the effects of CK18 downregulation on EMT, the expression of EMT-related molecules was assessed. As revealed in Fig. 6A and B, mRNA expression of E-cadherin was $15.1 \%(\mathrm{P}<0.01)$ and $36.5 \%(\mathrm{P}<0.001)$ lower in MCF-7/siCK18-7D and -3C cells, respectively, than in MCF-7 cells. The expression of $\mathrm{N}$-cadherin and vimentin genes was $188.0 \%(\mathrm{P}<0.01)$ and $387.0 \%(\mathrm{P}<0.001)$, and 108.9 and $291.9 \%(\mathrm{P}<0.01)$, greater in MCF-7/siCK18-7D and $-3 \mathrm{C}$ cells, 
A

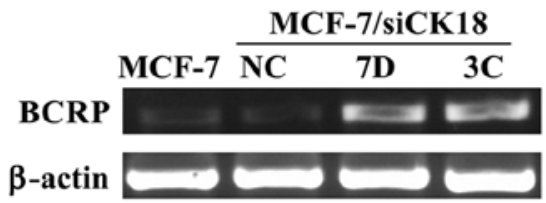

C

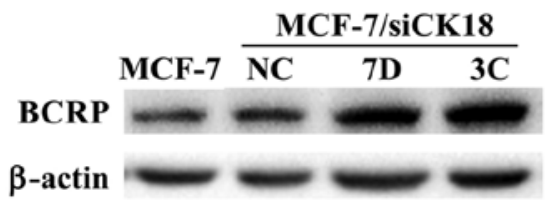

B

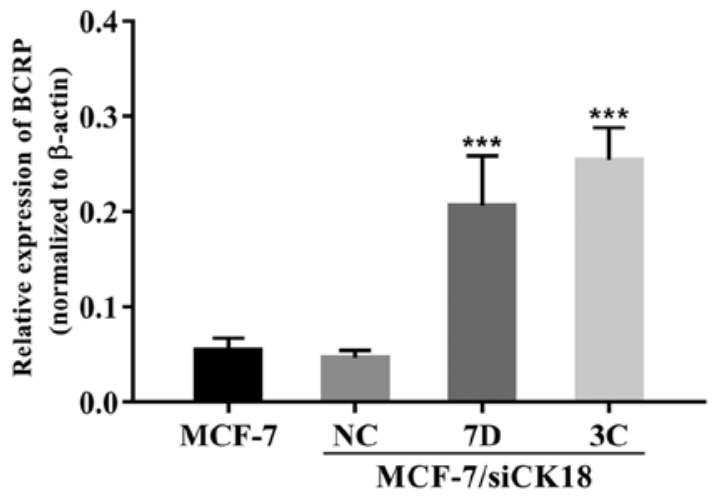

D

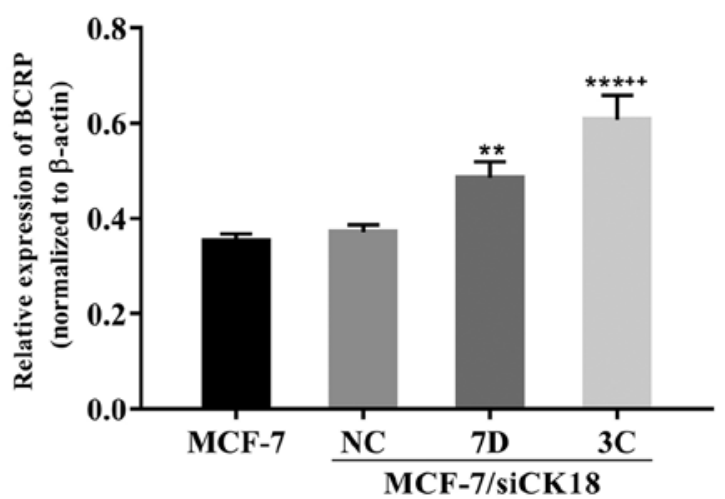

Figure 4. CK18 downregulation increases BCRP expression at the mRNA and protein levels in MCF-7 cells. (A) The expression of the BCRP gene in MCF-7, MCF-7/siNC, and MCF-7/siCK18 cells was detected using semi-quantitative reverse transcription PCR. (B) BCRP gene expression was normalized to the $\beta$-actin levels. Bar graphs represent the mean \pm standard deviation (SD) of three independent experiments. ${ }^{* * *} \mathrm{P}<0.001$ vs. MCF-7 cells. (C) Representative western blot images of the BCRP protein in MCF-7, MCF-7/siNC, and MCF-7/siCK18 cells. (D) BCRP protein expression was normalized to the $\beta$-actin levels. Bar graphs represent the mean \pm SD of three independent experiments. ${ }^{* *} \mathrm{P}<0.01$ and ${ }^{* * *} \mathrm{P}<0.001$ vs. MCF-7 cells; ${ }^{++} \mathrm{P}<0.01 \mathrm{vs}$. MCF-7/siCK18-7D cells. BCRP, breast cancer resistant protein.

respectively, than in MCF-7 cells. Representative western blotting revealed downregulation of E-cadherin and upregulation of $\mathrm{N}$-cadherin and vimentin in MCF-7/siCK18 cells (Fig. 6C). Densitometric analysis revealed1.2- $(\mathrm{P}<0.001)$ and 2.2 -fold $(\mathrm{P}<0.001)$ lower E-cadherin expression, 1.3- and 2.2-fold $(\mathrm{P}<0.001)$ greater $\mathrm{N}$-cadherin expression, and 1.4- $(\mathrm{P}<0.01)$ and 2.2-fold $(\mathrm{P}<0.001)$ greater vimentin expression in MCF-7/siCK18-7D and -3C cells, respectively, than in MCF-7 cells, while differences in the expression of these EMT-related markers were not statistically significant between MCF-7/siNC and MCF-7 cells (Fig. 6D). These results indicated that CK18 participated in BCRP-mediated MDR by modulating the expression of EMT-related factors in breast cancer cells.

CK18 downregulation activates $\mathrm{NF}-\kappa \mathrm{B} /$ Snail signaling in MCF-7 cells. The transcription factor Snail has been revealed to directly inhibit the expression of E-cadherin to regulate EMT $(26,27)$. Snail mRNA levels were $145.7 \%(\mathrm{P}<0.001)$ and $335.2 \%(\mathrm{P}<0.001)$ greater, and protein levels were $48.2 \%(\mathrm{P}<0.01)$ and $81.2 \%(\mathrm{P}<0.001)$ greater, in MCF-7/siCK18-7D and -3C cells, respectively, than in MCF-7 cells, while MCF-7/siNC cells contained levels of Snail that were approximately equal to those of MCF-7 $(\mathrm{P}>0.05)$ (Fig. 7A-D).

NF- $\mathrm{KB}$ p 65 has been reported to induce the activity of the Snail promoter $(28,29)$. CK18 knockdown led to a significant upregulation of NF- $\kappa \mathrm{B}$ p 65 mRNA and protein levels (Fig. 7E and F). Band intensity results revealed that NF- $\mathrm{kB}$ p65 mRNA expression was $107.2 \%(\mathrm{P}<0.01)$ and $355.2 \%(\mathrm{P}<0.001)$ greater, and protein was $291.5 \%(\mathrm{P}<0.001)$ and $459.8 \%(\mathrm{P}<0.001)$ greater, in MCF-7/siCK18-7D and $-3 \mathrm{C}$ cells, respectively, than in MCF-7 cells, while MCF-7/siNC cells showed non-significant increases in NF- $\mathrm{kB}$ p65 levels $(\mathrm{P}>0.05)$ (Fig. 7G and $\mathrm{H})$.

To further determine whether the NF- $\mathrm{kB} /$ Snail signaling pathway acts upstream of the EMT process, we observed the effects of pyrrolidinedithiocarbamate (PDTC), a specific NF- $\mathrm{KB}$ inhibitor, in MCF-7/MX cells. As revealed in Fig. 7I and J, after incubation with PDTC (50 and $100 \mu \mathrm{M}$ ) for $24 \mathrm{~h}$, the expression level of NF- $\kappa \mathrm{B}$ in MCF-7/MX cells was significantly decreased to $77.2 \%(\mathrm{P}<0.05)$ and $39.4 \%(\mathrm{P}<0.01)$, respectively. Treatment of MCF-7/MX cells with PDTC (50 and $100 \mu \mathrm{M})$ also resulted in significant reductions in the protein levels of Snail $(\mathrm{P}<0.05)$, which was accompanied by upregulation of $\mathrm{E}$-cadherin $(\mathrm{P}<0.05$ and $\mathrm{P}<0.01$, respectively $)$ and downregulation of $\mathrm{N}$-cadherin $(\mathrm{P}<0.05$ and $\mathrm{P}<0.01$, respectively) and vimentin $(\mathrm{P}<0.05$ and $\mathrm{P}<0.01$, respectively).

\section{Discussion}

Overexpression of BCRP, a newly discovered $\mathrm{ABC}$ transporter, may confer MDR to various types of human malignancies 

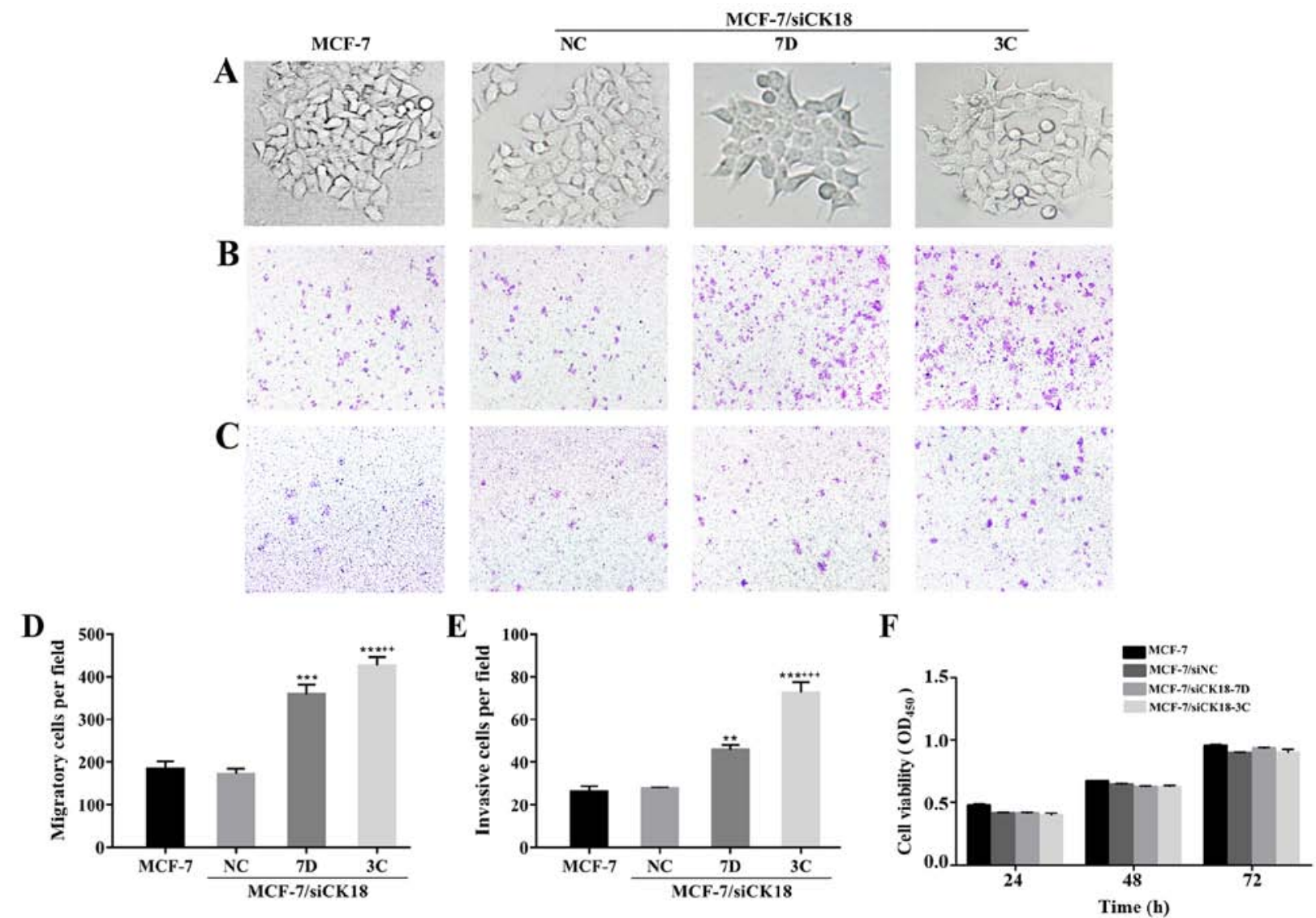

Figure 5. CK18 downregulation promotes the mesenchymal phenotype and enhances the migration and invasion abilities of MCF-7 cells. (A) Morphology of MCF-7, MCF-7/siNC, and MCF-7/siCK18 cells (magnification, x200). (B) The migration and (C) invasion abilities of MCF-7, MCF-7/siNC, and MCF-7/siCK18 cells were determined using Transwell cell culture chambers. (D) The migration and (E) invasion abilities were further quantified. ${ }^{* *} \mathrm{P}<0.01$ and ${ }^{* * *} \mathrm{P}<0.001$ vs. MCF-7 cells; ${ }^{++} \mathrm{P}<0.01$ and ${ }^{+++} \mathrm{P}<0.001$ vs. MCF-7/siCK18-7D cells. (F) Cell proliferation ability was measured using CCK-8 assay. Data are represented as the means \pm standard deviation (SD) of three independent experiments. CCK-8, Cell Counting Kit-8.

$\mathbf{A}$

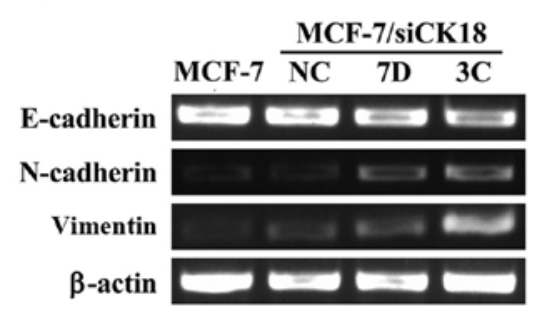

C

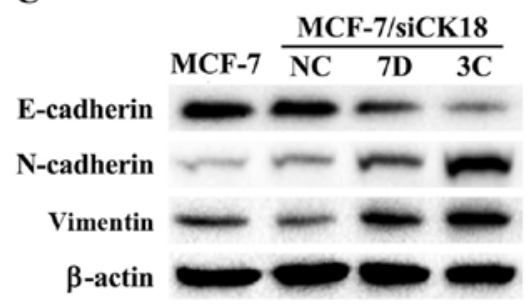

B

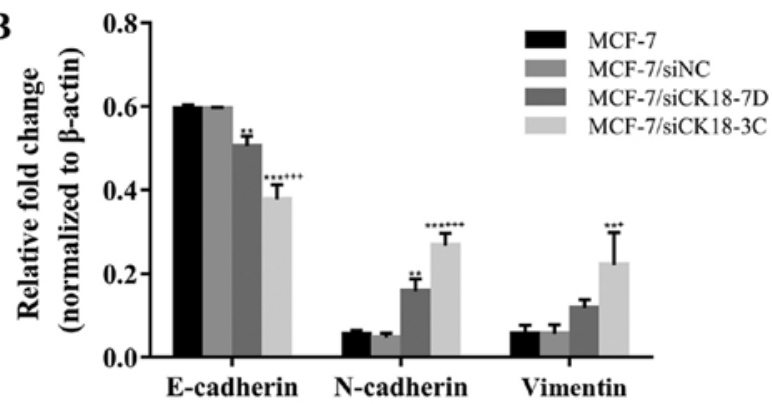

D

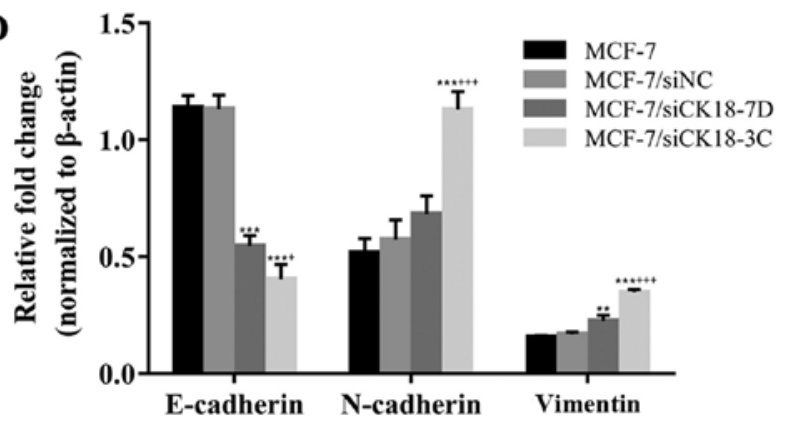

Figure 6. CK18 downregulation regulates the expression of EMT markers. (A) Western blotting revealed the expression levels of epithelial and mesenchymal protein markers in MCF-7, MCF-7/siNC, and MCF-7/siCK18 cells. (B) The protein expression of E-cadherin, N-cadherin, and vimentin was normalized to the $\beta$-actin levels. Bar graphs represent the mean \pm standard deviation (SD) of three independent experiments. ${ }^{* *} \mathrm{P}<0.01$ and ${ }^{* * * *} \mathrm{P}<0.001 \mathrm{vs}$. MCF-7 cells; ${ }^{+} \mathrm{P}<0.05$ and ${ }^{+++} \mathrm{P}<0.001$ vs. MCF-7/siCK18-7D cells. (C) The mRNA level of E-cadherin, N-cadherin, and vimentin in MCF-7, MCF-7/siNC, and MCF-7/siCK18 cells was determined by quantitative RT-PCR. (D) A bar diagram revealing densitometric quantified data for the ratios of E-cadherin, N-cadherin, and vimentin to $\beta$-actin mRNA. The graph displays the means $\pm \mathrm{SD}$ of three independent experiments. ${ }^{* *} \mathrm{P}<0.01$ and ${ }^{* * * *} \mathrm{P}<0.001$ vs. MCF-7 cells; ${ }^{+} \mathrm{P}<0.05$ and ${ }^{+++} \mathrm{P}<0.001$ vs. MCF-7/siCK18-7D cells. EMT, epithelial-mesenchymal transition. 
A

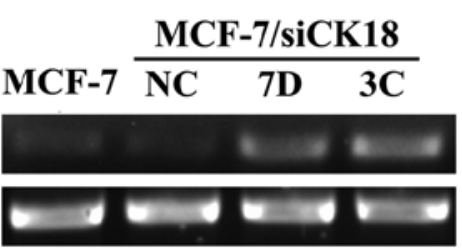

B

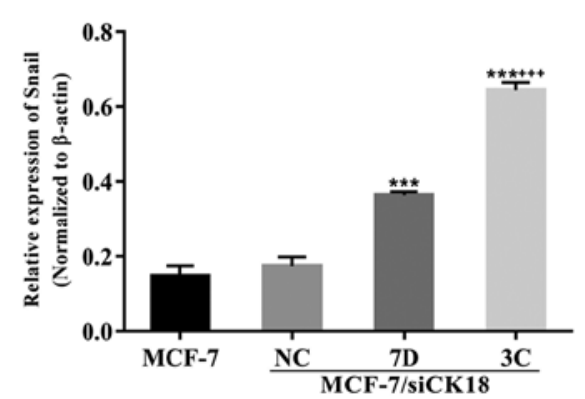

$\mathbf{E}$

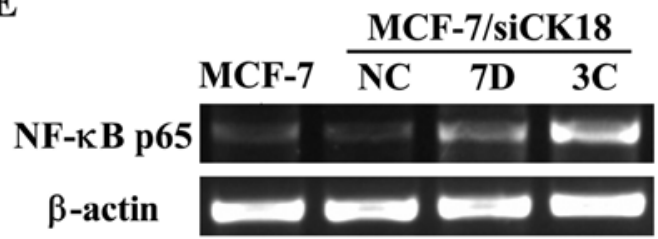

F

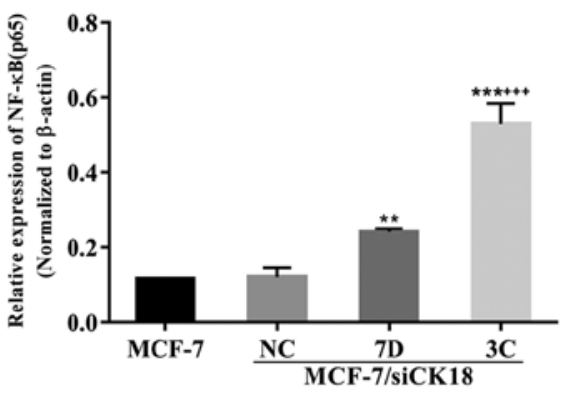

I

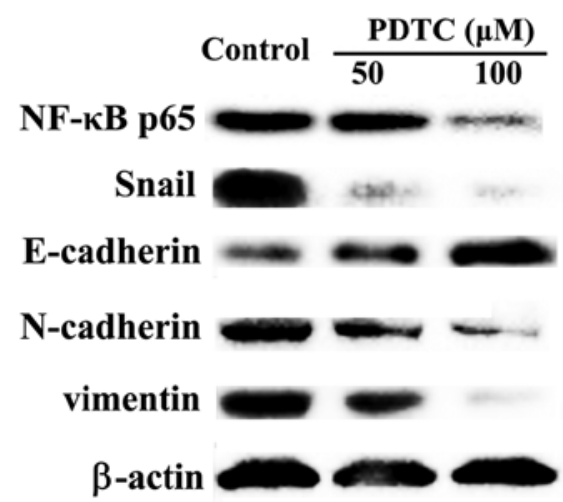

C

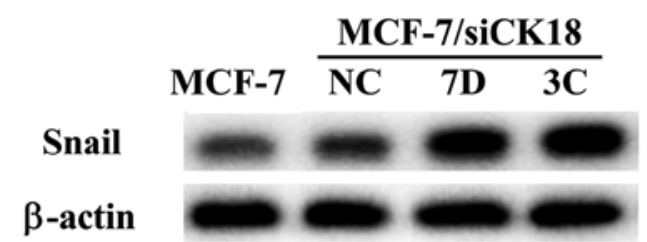

D

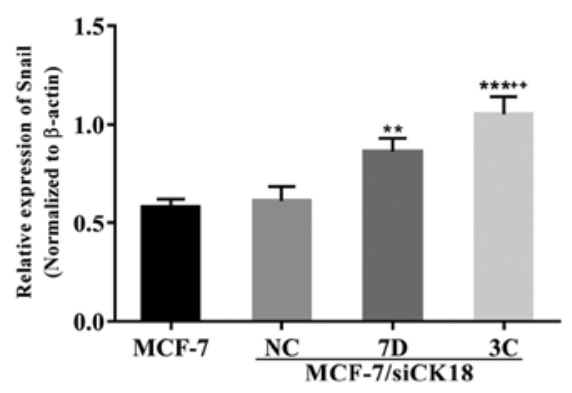

G

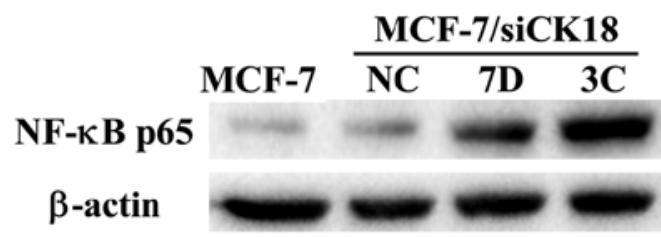

H

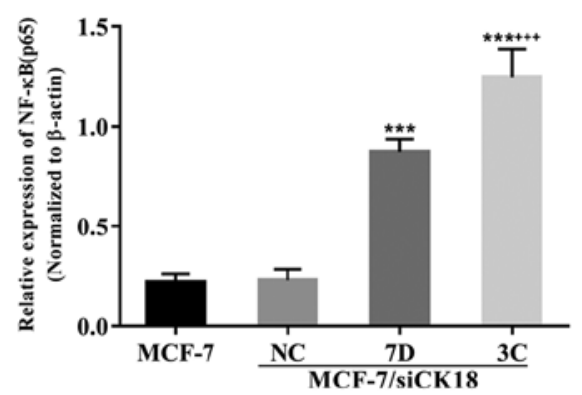

J

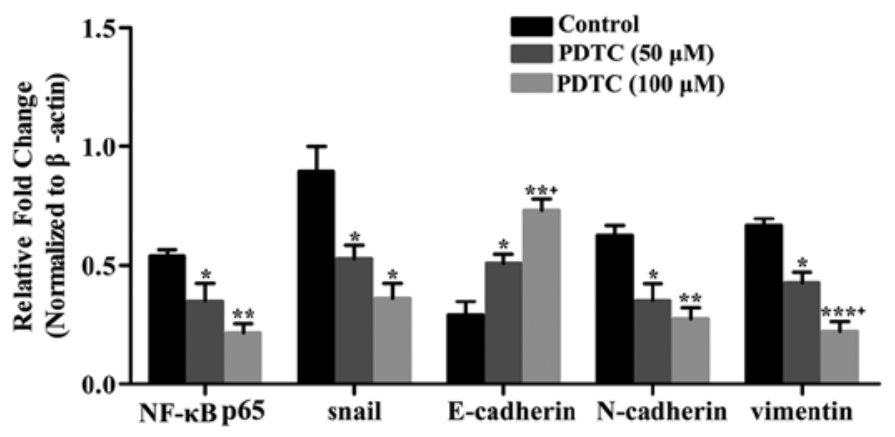

Figure 7. CK18 downregulation activates NF-кB/Snail signaling pathway in MCF-7 cells. Representative PCR images of (A) Snail and (E) NF- $\mathrm{B}$ in MCF-7, MCF-7/siNC, and MCF-7/siCK18 cells. The relative expression of (B) Snail and (F) NF-kB was further quantified. Representative western blot images of (C) Snail and (G) NF-kB in MCF-7, MCF-7/siNC and MCF-7/siCK18 cells. The protein expression of (D) Snail and (H) NF-kB was normalized to the $\beta$-actin levels. (I) Western blotting revealed the expression levels of NF-кB, Snail, E-cadherin, N-cadherin, and vimentin in MCF-7/MX cells in the absence or

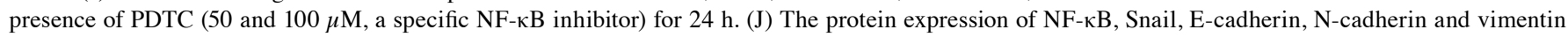
was normalized to the $\beta$-actin levels. The graph displays the means \pm standard deviation (SD) of three independent experiments. ${ }^{*} \mathrm{P}<0.05,{ }^{* *} \mathrm{P}<0.01$ and ${ }^{* * *} \mathrm{P}<0.001$ vs. MCF-7 cells; ${ }^{+} \mathrm{P}<0.05,{ }^{++} \mathrm{P}<0.01$ and ${ }^{+++} \mathrm{P}<0.001$ vs. MCF-7/siCK18-7D cells. PDTC, pyrrolidinedithiocarbamate.

including breast cancer (30-32). In addition to chemotherapy resistance, high BCRP expression promotes cellular resistance to radiation therapy (33). BCRP has also been identified as a cancer stem cell marker in diverse malignancies $(34,35)$. The correlations between high BCRP activity and decreased survival rate have been observed in clinical studies $(36,37)$. Attention has been focused on the contribution of BCRP to the promotion of MDR during cancer therapy, however, the mechanisms involved in BCRP upregulation in drug-resistant cancer cells remain largely unexplored. Therefore, overcoming 
BCRP-mediated MDR would contribute to cancer chemotherapy.

EMT-mediated MDR has been confirmed in various types of cancers, including breast cancer (38). Tumors with positive EMT markers can develop a subpopulation with a resistant phenotype, which can become a major obstacle to treatment (39). Overexpression of transcription factors that mediate EMT was reported to lead to ABC transporter upregulation and subsequent MDR in breast cancer cells (40). Various EMT-related factors have been revealed to be used to indicate the prognosis of chemotherapy in breast cancer patients $(41,42)$. A previous study demonstrated that BCRP expression in breast cancer cells could be regulated during EMT (43). In the present study, we observed that BCRP-overexpressing MCF-7/MX cells exhibited a typical mesenchymal phenotype, more aggressive and invasive behavior, downregulation of E-cadherin, and upregulation of $\mathrm{N}$-cadherin and vimentin, compared with parental MCF-7 cells. These observations strongly indicated that EMT was closely associated with BCRP-mediated chemoresistance in MCF-7/MX cells.

Reduction or loss of epithelial keratins has been considered a hallmark of EMT (44).CK18 has been revealed to be necessary for initiation of EMT in breast epithelial cells and is frequently used as an epithelial EMT marker (15). Accordingly, reducing CK18 expression increased the aggressiveness of established breast cancer cell lines (45). Consistent with these findings, our current study revealed that reduction of CK18 expression in MCF-7 cells promoted the EMT process as evidenced by mesenchymal morphology, enhanced migration and invasion, and altered expression of EMT markers. Furthermore, CK18 downregulation resulted in reduced sensitivity of $\mathrm{MCF}-7$ human breast cancer cells to chemotherapeutic agents and increased BCRP expression, suggesting that CK18 downregulation is a candidate promoter of BCRP-mediated MDR. Several studies have revealed that high CK18 expression was correlated with a good prognosis $(19,20)$. In the present study, we observed that CK18 expression was significantly decreased in breast cancer tissues, and low CK18 expression was found to be associated with TNM stage and lymph node metastasis in breast cancer. Kaplan-Meier analysis revealed that patients with CK18 low expression presented poorer prognosis compared with those with CK18 high expression. Based on these results, it was concluded that downregulation of CK18 conferred BCRP-mediated resistance to breast cancer MCF-7 cells partly via EMT induction, thereby enhancing tumor invasion and metastasis and promoting MDR; this may provide an explanation for the poor prognostic outcomes in breast cancer patients with CK18-low tumors.

The mechanisms by which CK18 downregulation induces EMT and confers BCRP-mediated MDR in breast cancer MCF-7 cells are worthy of investigation. Numerous studies have indicated that the $\mathrm{NF}-\kappa \mathrm{B} / \mathrm{Snail}$ signaling pathway promotes metastasis/invasion through EMT $(29,46)$. The expression of Snail can be regulated by NF- $\kappa \mathrm{B}$ signaling through both transcriptional and post-translational mechanisms $(29,47)$. The activation of $\mathrm{NF}-\kappa \mathrm{B}$ may induce significantly increased expression of Snail, which directly suppresses transcription of E-cadherin (48) and upregulates $\mathrm{N}$-cadherin and vimentin expression (49), subsequently inducing EMT and metastasis/invasion in cancer cells. In the present study, knockdown

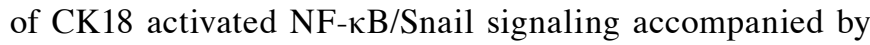
attenuation of E-cadherin and upregulation of $\mathrm{N}$-cadherin and vimentin expression, which clearly promoted the malignant phenotype of MCF-7 cells. These results indicated that CK18 downregulation may induce EMT through the NF- $\kappa \mathrm{B} / \mathrm{Snail}$ signaling pathway in breast cancer MCF-7 cells.

EMT-mediated therapeutic resistance has been observed in several types of cancers. Although the mechanisms by which EMT regulates MDR are not clearly understood, accumulating evidence suggests that EMT may result in overexpression of ABC transporters, thereby conferring MDR to tumor cells $(8,50)$. Several ABC transporters have been demonstrated to contain binding sites for EMT-related transcription factors, including Snail (40). Overexpression of Snail has been revealed to be highly correlated with BCRP-mediated MDR (51). Snail has been frequently reported to promote tumor progression and to predict prognosis $(52,53)$. NF- $\kappa \mathrm{B} /$ Snail signaling has been demonstrated to be required for the EMT process in human breast cancer cells (54). Therefore, we surmised that downregulation of CK18 in MCF-7 cells activated the $\mathrm{NF}-\kappa \mathrm{B} /$ Snail signaling pathway and induced the EMT process, consequently enhancing the expression and activity of BCRP.

In conclusion, our study demonstrated that CK18 was significantly downregulated during the progression of human breast cancer as well as during invasion, metastasis, and acquisition of drug resistance. Downregulation of CK18 was revealed to play crucial roles in the regulation of metastasis and MDR of breast cancer, which is helpful for prognosis assessment in breast cancer. Further pre-clinical and clinical studies may be required to evaluate the role of CK18 as a potential predictor of breast cancer.

\section{Acknowledgements}

We would like to thank the patients with breast cancer and their families for participation. We would also like to thank Dr Liwu Xie (Department of Pathology, Shanxi Cancer Hospital) and Wenjing Du (Department of Radiation, Shanxi Cancer Hospital) for their contributions to the collection of breast cancer cases.

\section{Funding}

The present study was funded by grants from the National Natural of Science Foundation of China (no. 81502641), the Fund for Shanxi Key Subjects Construction (FSKSC) and the Fund for Shanxi '1331 Project' Key Subjects Construction (1331KSC).

\section{Availability of data and materials}

The datasets of IHC and/or analyzed during the study are available from the corresponding author on reasonable request. Other datasets generated or analyzed during this study are included in this published article.

\section{Authors' contributions}

RS was responsible for the design of the experiment and the writing of the manuscript. $\mathrm{CW}$ and $\mathrm{ZW}$ performed the IHC 
of the breast cancer tissue. NF and CW analyzed the data of breast cancer patient. CW, DZ, NF and LL performed the western blot analysis and PCR analysis of the experiment. LL and DZ were contributed to the migration and invasion of cells. RS and CW participated in the determination of cell mechanics. RS and HZ performed the statistical analysis. JX and YW performed the technical and material support. All authors read and approved the manuscript and agree to be accountable for all aspects of the research in ensuring that the accuracy or integrity of any part of the work are appropriately investigated and resolved.

\section{Ethics approval and consent to participate}

Use of the specimens was approved by the Ethics Committee of Shanxi Cancer Hospital. All experimental protocols were approved by the Ethics Committee of Shanxi Medical University (Taiyuan, China), and in line with the 1964 Helsinki declaration and its later amendments or comparable ethical standards. All samples were obtained before treatment according to the guidelines of the local ethics committees. Written informed consent was received from all participants.

\section{Patient consent for publication}

Not applicable.

\section{Competing interests}

The authors state that they have no competing interests.

\section{References}

1. Königsberg R, Obermayr E, Bises G, Pfeiler G, Gneist M, Wrba F, de Santis M, Zeillinger R, Hudec M and Dittrich C: Detection of EpCAM positive and negative circulating tumor cells in metastatic breast cancer patients. Acta Oncol 50: 700-710, 2011.

2. Hart CD, Migliaccio I, Malorni L, Guarducci C, Biganzoli L and Di Leo A: Challenges in the management of advanced, ER-positive, HER2-negative breast cancer. Nat Rev Clin Oncol 12: 541-552, 2015.

3. Saeki T, Tsuruo T, Sato W and Nishikawsa K: Drug resistance in chemotherapy for breast cancer. Cancer Chemother Pharmacol 56 (Suppl 1): 84-89, 2005.

4. Jin Y, Zhang W, Wang H, Zhang Z, Chu C, Liu X and Zou Q: EGFR/HER2 inhibitors effectively reduce the malignan potential of MDR breast cancer evoked by P-gp substrates in vitro and in vivo. Oncol Rep 35: 771-778, 2016.

5. Wang W, Zou L, Zhou D, Zhou Z, Tang F, Xu Z and Liu X: Overexpression of ubiquitin carboxyl terminal hydrolase-L1 enhances multidrug resistance and invasion/metastasis in breast cancer by activating the MAPK/Erk signaling pathway. Mol Carcinog 55: 1329-1342, 2016.

6. Lu LS, Chen L, Ding WX, Li K and Wu JJ: Elevated expression of both MDR1 and MMP-2 genes in metastasized lymph node of invasive ductal breast cancer. Eur Rev Med Pharmacol Sci 16: 2037-2043, 2012.

7. Matsuo K, Eno ML, Ahn EH, Shahzad MM, Im DD, Rosenshein NB and Sood AK: Multidrug resistance gene (MDR-1) and risk of brain metastasis in epithelial ovarian, fallopian tube, and peritoneal cancer. Am J Clin Oncol 34: 488-493, 2011.

8. Yang J and Weinberg RA: Epithelial-mesenchymal transition: At the crossroads of development and tumor metastasis. Dev Cell 14: 818-829, 2008.

9. Thiery JP and Sleeman JP: Complex networks orchestrate epithelial-mesenchymal transitions. Nat Rev Mol Cell Biol 7: 131-142, 2006

10. Grünert $S$, Jechlinger $M$ and Beug $H$ : Diverse cellular and molecular mechanisms contribute to epithelial plasticity and metastasis. Nat Rev Mol Cell Biol 4: 657-665, 2003.
11. Huber MA, Kraut N and Beug H: Molecular requirements for epithelial-mesenchymal transition during tumor progression. Curr Opin Cell Biol 17: 548-558, 2005.

12. Dave B,Mittal V, Tan NM and Chang JC: Epithelial-mesenchymal transition, cancer stem cells and treatment resistance. Breast Cancer Res 14: 202, 2012.

13. Wang Y and Zhou BP: Epithelial-mesenchymal transition - A Hallmark of breast cancer metastasis. Cancer Hallm 1: 38-49, 2013

14. Makino T, Yamasaki M, Takeno A, Shirakawa M, Miyata H, Takiguchi S, Nakajima K, Fujiwara Y, Nishida T, Matsuura N, et al: Cytokeratins 18 and 8 are poor prognostic markers in patients with squamous cell carcinoma of the oesophagus. Br J Cancer 101: 1298-1306, 2009.

15. Jung H, Kim B, Moon BI and Oh ES: Cytokeratin 18 is necessary for initiation of TGF- $\beta 1$-induced epithelial-mesenchymal transition in breast epithelial cells. Mol Cell Biochem 423: 21-28, 2016.

16. Oshima RG, Baribault $\mathrm{H}$ and Caulín C: Oncogenic regulation and function of keratins 8 and 18. Cancer Metastasis Rev 15: 445-471, 1996.

17. Schaafsma HE, Van Der Velden LA, Manni JJ, Peters H, Link M, Rutter DJ and Ramaekers FC: Increased expression of cytokeratins 8,18 and vimentin in the invasion front of mucosal squamous cell carcinoma. J Pathol 170: 77-86, 1993.

18. Luan Y, Chao S, Ju ZY, Wang J, Xue X, Qi TG, Cheng GH and Kong F: Therapeutic effects of baicalin on monocrotaline-induced pulmonary arterial hypertension by inhibiting inflammatory response. Int Immunopharmacol 26: 188-193, 2015.

19. Woelfle U, Sauter G, Santjer S, Brakenhoff R and Pantel K: Down-regulated expression of cytokeratin 18 promotes progression of human breast cancer. Clin Cancer Res 10: 2670-2674, 2004.

20. Schaller G, Fuchs I, Pritze W, Ebert A, Herbst H, Pantel K, Weitzel $\mathrm{H}$ and Lengyel E: Elevated keratin 18 protein expression indicates a favorable prognosis in patients with breast cancer. Clin Cancer Res 2: 1879-1885, 1996.

21. Yoon HN, Yoon SY, Hong JH and Ku NO: A mutation in keratin 18 that causes caspase-digestion resistance protects homozygous transgenic mice from hepatic apoptosis and injury. J Cell Sci 130: 2541-2550, 2017.

22. Leifeld L, Kothe S, Söhl G, Hesse M, Sauerbruch T, Magin TM and Spengler U: Keratin 18 provides resistance to Fas-mediated liver failure in mice. Eur J Clin Invest 39: 481-488, 2009.

23. Shi R, Zhu D, Wei Z, Fu N, Wang C, Liu L, Zhang H, Liang Y, Xing J, Wang X, et al: Baicalein attenuates monocrotaline-induced pulmonary arterial hypertension by inhibiting endothelial-tomesenchymal transition. Life Sci 207: 442-450, 2018.

24. Livak KJ and Schmittgen TD: Analysis of relative gene expression data using real-time quantitative PCR and the 2(-Delta Delta C(T)) method. Methods 25: 402-408, 2001.

25. Shi R, Wei Z, Zhu D, Fu N, Wang C, Yin S, Liang Y, Xing J, Wang $\mathrm{X}$ and Wang Y: Baicalein attenuates monocrotalineinduced pulmonary arterial hypertension by inhibiting vascular remodeling in rats. Pulm Pharmacol Ther 48: 124-135, 2018.

26. Batlle E, Sancho E, Francí C, Domínguez D, Monfar M, Baulida J and García De Herreros A: The transcription factor snail is a repressor of E-cadherin gene expression in epithelial tumour cells. Nat Cell Biol 2: 84-89, 2000.

27. Cano A, Pérez-Moreno MA, Rodrigo I, Locascio A, Blanco MJ, del Barrio MG, Portillo F and Nieto MA: The transcription factor snail controls epithelial-mesenchymal transitions by repressing E-cadherin expression. Nat Cell Biol 2: 76-83, 2000.

28. Song R, Song H, Liang Y, Yin D, Zhang H, Zheng T, Wang J, Lu Z, Song X, Pei T, et al: Reciprocal activation between ATPase inhibitory factor 1 and NF- $\mathrm{BB}$ drives hepatocellular carcinoma angiogenesis and metastasis. Hepatology 60: 1659-1673, 2014.

29. Barberà MJ, Puig I, Domínguez D, Julien-Grille S, GuaitaEsteruelas S, Peiró S, Baulida J, Francí C, Dedhar S, Larue L, et al: Regulation of Snail transcription during epithelial to mesenchymal transition of tumor cells. Oncogene 23: 7345-7354, 2004.

30. Allen JD, Brinkhuis RF, Wijnholds J and Schinkel AH: The mouse Bcrp1/Mxr/Abcp gene: Amplification and overexpression in cell lines selected for resistance to topotecan, mitoxantrone, or doxorubicin. Cancer Res 59: 4237-4241, 1999.

31. Doyle L and Ross DD: Multidrug resistance mediated by the breast cancer resistance protein BCRP (ABCG2). Oncogene 22: 7340-7358, 2003.

32. Volk EL, Farley KM, Wu Y, Li F, Robey RW and Schneider E: Overexpression of wild-type breast cancer resistance protein mediates methotrexate resistance. Cancer Res 62: 5035-5040, 2002. 
33. Ingram WJ, Crowther LM, Little EB, Freeman R, Harliwong I, Veleva D, Hassall TE, Remke M, Taylor MD and Hallahan AR: ABC transporter activity linked to radiation resistance and molecular subtype in pediatric medulloblastoma. Exp Hematol Oncol 2: 26, 2013.

34. Golebiewska A, Brons NH, Bjerkvig R and Niclou SP: Critical appraisal of the side population assay in stem cell and cancer stem cell research. Cell Stem Cell 8: 136-147, 2011.

35. Wu C and Alman BA: Side population cells in human cancers. Cancer Lett 268: 1-9, 2008.

36. Benderra Z, Faussat AM, Sayada L, Perrot JY, Chaoui D, Marie JP and Legrand O: Breast cancer resistance protein and P-glycoprotein in 149 adult acute myeloid leukemias. Clin Cancer Res 10: 7896-7902, 2004

37. Uggla B, Ståhl E, Wågsäter D, Paul C, Karlsson MG, Sirsjö A and Tidefelt U: BCRP mRNA expression v. clinical outcome in 40 adult AML patients. Leuk Res 29: 141-146, 2005.

38. Nantajit D, Lin D and Li JJ: The network of epithelial-mesenchymal transition: Potential new targets for tumor resistance. J Cancer Res Clin Oncol 141: 1697-1713, 2015.

39. Shintani Y, Okimura A, Sato K, Nakagiri T, Kadota Y, Inoue M Sawabata N, Minami M, Ikeda N, Kawahara K, et al: Epithelial to mesenchymal transition is a determinant of sensitivity to chemoradiotherapy in non-small cell lung cancer. Ann Thorac Surg 92: 1794-1804, discussion 1804, 2011.

40. Saxena M, Stephens MA, Pathak H and Rangarajan A: Transcription factors that mediate epithelial-mesenchymal transition lead to multidrug resistance by upregulating $\mathrm{ABC}$ transporters. Cell Death Dis 2: e179, 2011.

41. Fanelli MA, Montt-Guevara M, Diblasi AM, Gago FE, Tello O, Cuello-Carrión FD, Callegari E, Bausero MA and Ciocca DR: $\mathrm{P}$-cadherin and beta-catenin are useful prognostic markers in breast cancer patients; beta-catenin interacts with heat shock protein Hsp27. Cell Stress Chaperones 13: 207-220, 2008

42. Taube JH, Herschkowitz JI, Komurov K, Zhou AY, Gupta S Yang J, Hartwell K, Onder TT, Gupta PB, Evans KW, et al: Core epithelial-to-mesenchymal transition interactome gene-expression signature is associated with claudin-low and metaplastic breast cancer subtypes. Proc Natl Acad Sci USA 107: 15449-15454, 2010

43. Yin L, Castagnino $P$ and Assoian RK: ABCG2 expression and side population abundance regulated by a transforming growth factor beta-directed epithelial-mesenchymal transition. Cancer Res 68: 800-807, 2008 .
44. Polyak K and Weinberg RA: Transitions between epithelial and mesenchymal states: Acquisition of malignant and stem cell traits. Nat Rev Cancer 9: 265-273, 2009.

45. Bühler H and Schaller G: Transfection of keratin 18 gene in human breast cancer cells causes induction of adhesion proteins and dramatic regression of malignancy in vitro and in vivo. Mol Cancer Res 3: 365-371, 2005.

46. Kudo-Saito C, Shirako H, Takeuchi T and Kawakami Y: Cancer metastasis is accelerated through immunosuppression during Snail-induced EMT of cancer cells. Cancer Cell 15: 195-206, 2009.

47. Wu Y, Deng J, Rychahou PG, Qiu S, Evers BM and Zhou BP: Stabilization of snail by NF-kappaB is required for inflammationinduced cell migration and invasion. Cancer Cell 15: 416-428, 2009.

48. Min C, Eddy SF, Sherr DH and Sonenshein GE: NF-kappaB and epithelial to mesenchymal transition of cancer. J Cell Biochem 104: 733-744, 2008.

49. Lamouille S, Xu J and Derynck R: Molecular mechanisms of epithelial-mesenchymal transition. Nat Rev Mol Cell Biol 15: 178-196, 2014.

50. Takano M, Yamamoto $C$, Yamaguchi K, Kawami $M$ and Yumoto R: Analysis of TGF- $\beta 1$ - and drug-induced epithelialmesenchymal transition in cultured alveolar epithelial cell line RLE/Abca3. Drug Metab Pharmacokinet 30: 111-118, 2015.

51. Chen WJ, Wang H, Tang Y, Liu CL, Li HL and Li WT: Multidrug resistance in breast cancer cells during epithelial-mesenchymal transition is modulated by breast cancer resistant protein. Chin J Cancer 29: 151-157, 2010.

52. Kwon CH, Park HJ, Choi JH, Lee JR, Kim HK, Jo HJ, Kim HS, Oh N, Song GA and Park DY: Snail and serpinA1 promote tumor progression and predict prognosis in colorectal cancer. Oncotarget 6: 20312-20326, 2015.

53. Yang Z, Zhang B, Liu B, Xie Y and Cao X: Combined Runx 2 and Snail overexpression is associated with a poor prognosis in breast cancer. Tumour Biol 36: 4565-4573, 2015.

54. Huang T, Chen $Z$ and Fang L: Curcumin inhibits LPS-induced EMT through downregulation of NF- $\kappa \mathrm{B}$-Snail signaling in breast cancer cells. Oncol Rep 29: 117-124, 2013. 